\title{
Full changing of the load-bearing wall of the bunker's building of the coal mine
}

\author{
Grygorii Gasii ${ }^{1 *}$, Viacheslav Shushkevych ${ }^{1}$, Olena Hasii $^{2}$, and Oleksandr Telichenko ${ }^{1}$ \\ ${ }^{1}$ Sumy National Agrarian University, Department of Construction Technology, 160 Kondratieva St., \\ 40021 Sumy, Ukraine \\ ${ }^{2}$ Poltava University of Economics and Trade, Institute of Economics, Management and Information \\ Technology, 3 Kovalia St., 36014 Poltava, Ukraine
}

\begin{abstract}
The main and very painful problem of the usages division of enterprises in Ukraine is the running roofing of buildings. Regrettably, in the climatic zone of Ukraine, all buildings, except the influence of the water, are subjected to the more significant influence of the variable cycles "freeze-unfreeze". At first, the distractions due to "freeze-unfreeze" cycles are of the form of make-up defects. However, since the time this brings about such an essential reduction of the cross-section of the wall that appears threat partial or full loss carrying abilities of the wall. An additional problem turns out to be else and that circumstance that very often such buildings can not be stopped from usage for the realization of the repair. To such buildings, for instance, can be ranked the bunker's building of the "Oktiabrska" mines (Ukraine), which is the high-altitude building with very heavy conditions of work. The carrying walls from the silicate brick very vulnerable to moistening and following cycles of the "freeze-unfreeze". All this has brought about essential destruction of the carrying wall and threat of the full destruction of the building. The technique of the reconstruction in like events can be extremely varied. The method of the full changing of the carrying wall of the bunker's building is offered, which does not require stops the production.
\end{abstract}

\section{Introduction}

Diagnostic of the technical condition of the building structures is an independent way of building activity. It covers the complex of the questions, in accordance with ensuring the serviceability of the buildings, with undertaking repair and reconstruction work, as well as with the development of the design documentation on reconstructions of the structures and buildings. The volume of the conducted diagnostics of the buildings and structures increasing year by year. This is due to row factor physical and obsolescence, reconstruction of the buildings of the industrial enterprises, changing of the property categories, and cutting of increasing of the prices on-premises, land sites. Particularly, it is important to undertake the diagnostic after different sorts of technical and natural influence, at reconstructions of the old houses and buildings. In the process of the usage of the buildings

* Corresponding author: gasiigm@gmail.com 
as a consequence of various reasons occurs the physical wear-out, reduction, and loss of their carrying abilities, deformation both separate elements and buildings as a whole. For development activities on the reconstruction of working quality of structures, the necessary undertaking of their diagnostic for the reason revealing of the premature wear-out and reduction of their carrying abilities. At present diagnostic of the houses and buildings in that or other volume concern with the organization miscellaneous, joint-stock companies, the majority from which earlier did not concern with these types of building activity. As a result quite often appear work low-grade, weakly reflecting modern achievements in the field of building technology and facilities of the measurements. Practically not to conduct the generalization a result of diagnostic conducted even specialized organization, that negatively reflects on the most further improvement of the methods of the diagnostic and reconstructions of the buildings and structures. However, practically are absent work, connected with diagnostic of working quality both separate structures and buildings as a whole. In addition, the literature on modern methods of the diagnostic of the building extremely limited. Obviously, that diagnostics of the structures and buildings of the different branches of industry must be executed by specialized organizations and specialists, processing knowledge in the most different areas of the building science, as well as knowing particularities of the technological processes in an industrial building. Considering that in high educational institutions preparation of specialists on diagnostic of the buildings with provision for specific appropriate branches of industry, as well as insufficient reflection in the literature of the questions of the diagnostics, the problem of corresponding publication remains an actual and urgent problem. In this work, authors try partly to fill this gap.

The main purpose of the investigation is to suggest the strategy of the reconstruction, which allows changing the load-carrying wall of the upper floor of the building of the bunker without the stop of the main technological process.

\section{Methods}

Method of the research and decision making, which is used in this work, - this far-famed exploratory method of the analysis and syntheses. On the initial stage of the work on reconstructions must be collected information about methods of reconstruction and results of testing given type structures [1 - 13]. Besides this, information about available customer materials and equipment must be collected also. Also must be worded special requirements of the customer for particularities, terms, and conditions of the execution of this work. These requirements form, so named, "initial restrictions" on work execution on reconstruction. Completely this information must be carefully analyzed. Finally, the method of the execution of reconstruction work is synthesized. Depending on that, insofar is carefully executed this work, depends on the success of the reconstruction as a whole.

\section{Results and discussion}

Brickwork leaves their root in deep antiquity. History has given builders it is enough time to create an ensemble of the methods of the repair of the reinforcement and recovering the brickwork [14-20]. Today we can restore the brick wall by multiform ways:

a) by concrete - reinforced concrete cartridge clip; cartridge clip with cement solution;

b) by metallic elements - tensed (anchors) and non-tensed (metallic lag);

c) by composite materials;

d) by injection treatment;

e) by the way of full change. 
The choice of the concrete method must be realized on the base of the all-round analysis of the conditions of the reconstruction. The leading issue of the usages division of different enterprises and organizations in Ukraine are running roofing of industrial enterprises, civil and public buildings, and so on.

Unfortunately, in the Ukrainian's climatic zone, all buildings, except the influence of the water, are subjected to the additional significant influence of the variable cycles "freeze-unfreeze", during season change. That destruction of the brick is developed by a quick rate if the brick walls will be not protected by special waterproof materials or means. First of all, such destructions are of the form of make-up defects. But since the time this brings about such essential reduction of the cross-section of the wall, that appears threat partial or full loss carrying abilities of the wall. Besides, the problem turns out to be else and that circumstance that very often such buildings can not be stopped from usage for the realization of the repair. To such buildings, for instance, can be ranked the bunker's building of the "Oktiabrska" coal mines, which is the high-altitude building with very heavy exploitation conditions.

The carrying walls from the brick [21-26] very vulnerable to moistening and following cycles of the "freeze-unfreeze". All this has brought about essential destruction of the carrying wall and threat of the full destruction of the building (Fig. 1, $a$ ).

This building is intended for loading of the coal in railway coaches. In this building are situated heavy steel bunkers. In these bunkers, the coal is delivered by means of a conveyor. This building is a vitally important element of the production cycle of the mine and can not be complete of even partly stopped for the realization of repair work on the reconstruction of the carrying abilities of the wall.

Fig. 1, $b$ shows the general view of the building of the bunker.

$a$

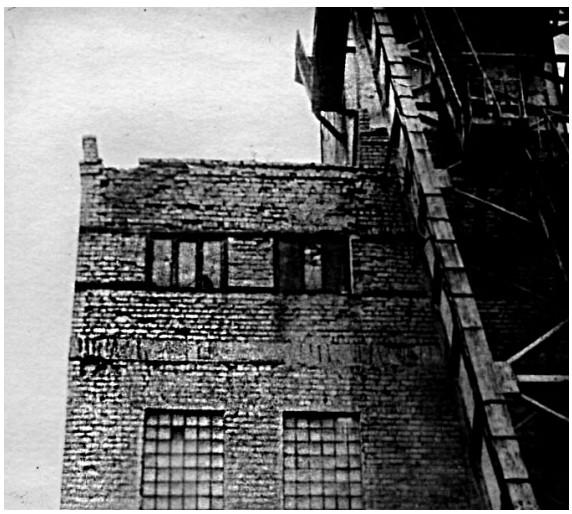

$b$

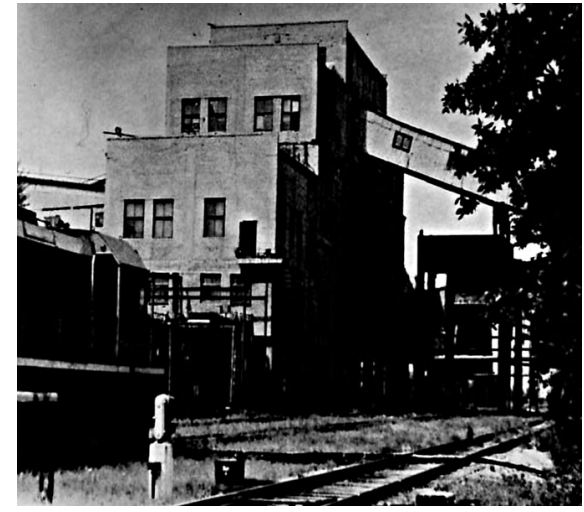

Fig. 1. Destruction of the load-carrying wall of the upper floor $(a)$ and general view of the building of the bunker of the mine "Oktiabrska" $(b)$.

On the initial stage of development of the project of the reconstruction, some initial conditions were worded by the customer.

The first condition. The full exception of the high-altitude work outside the building. This condition $\mathrm{s}$ caused by the need for the full exception of the simultaneous work execution on several levels. Because reconstruction was expected to execute without the stop of the main technological process in the building of the bunker. This means that the shipment of coal must not stop. And on consequently must not stop work on presenting of coaches and their sorting. And must not stop functioning (working) the people at a rate of land. Thereby, the creation of the monolithic cartridge around the wall turns out to be 
unacceptable.

The second condition. Need the use the metal available on the storehouse of the enterprise. Full, as far as possible, the exception of additional buying the metal for a given project. As can be seen from photography, the method of the tire, that is to say, the metallic band, was already applying earlier. However, it can not prevent the destruction of the wall and reduction of the toughness of the brick under influence natural factors.

The third condition. Ideal possibility of use available at the enterprise of the broad nomenclature all manner supporting system. Without needing to buy what or extras equipment.

The fourth condition. Mine - this is an enterprise of the unceasing technological cycle, which works in three changes $b$ can not be stopped for the execution of reconstructions work. So, construction projects must be to provide execution of all works for reconstructions without stopping of the main technological process in the bunker building.

Generalization of all said conditions has brought about the strategic problem of the full changing of the load-bearing wall of the upper floor of the building of the bunker. Such a solution can be referred to as categories of the heuristic solutions under the influence of the initial conditions. Constructively this problem was expected to execute by installation on the last floor of the building of the bunker of the system with two panels (Fig. 2).

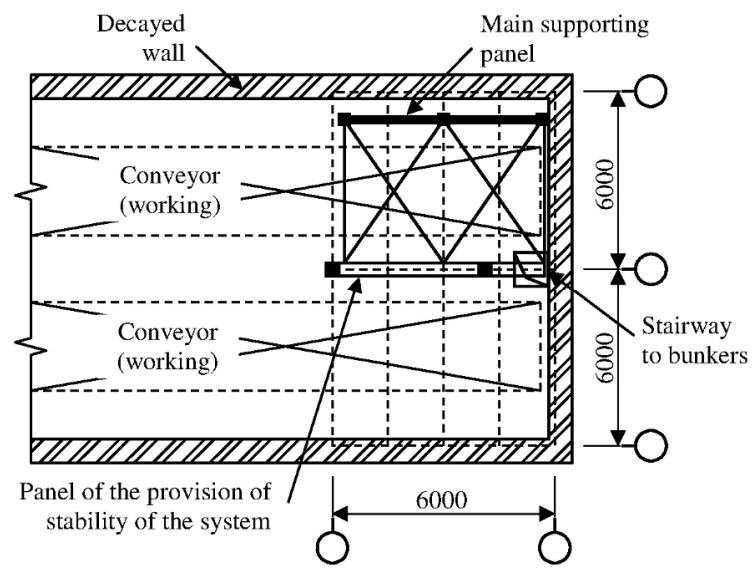

Fig. 2. Plan of the installation of the system of the panels on the upper floor of the building of the bunker.

The main supporting panel was situated directly near the wall, which must be replaced. The main function of this panel was concluded in that to upload, "switch off" from work, the load-bearing wall, and take out the load of it. For this, in this spatial panel was provided, rolling in the vertical plane, carrier horizontal supporting beam.

This beam leans on a hydraulic shaft lining (Figs. 3 - 5). By means of supporting beam and hydraulic shaft lining, the covering slabs of the building of the bunker were lifted under the load-bearing wall on 50-80 $\mathrm{mm}$. Such a system has allowed us to upload and completely unmount whole the load-carrying wall. The main supporting panel has allowed holding covering slabs during the installation of the new wall and then sailed to lower them on the wall. For providing the vertical position of the main supporting panel during execution all reconstructions work, was provided an additional panel of the provision of stability of the system (Fig. 6). 
$a$

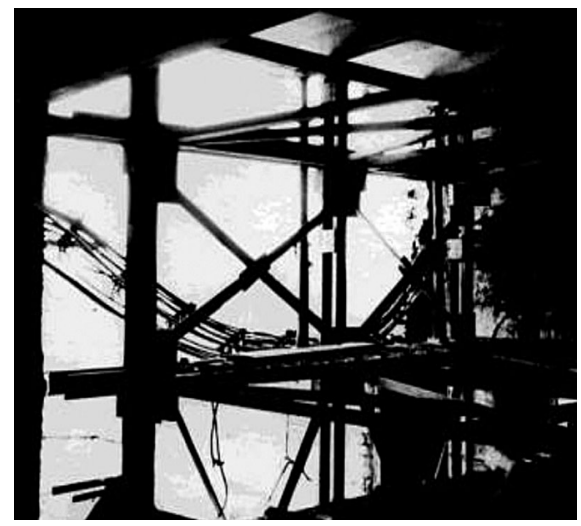

$b$

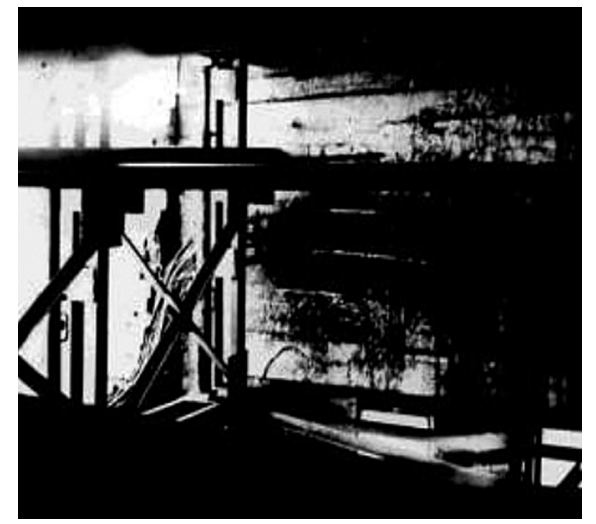

Fig. 3. The main supporting panel in worker order $(a)$ and the hydraulic shaft lining beside butt end wall $(b)$.

$a$

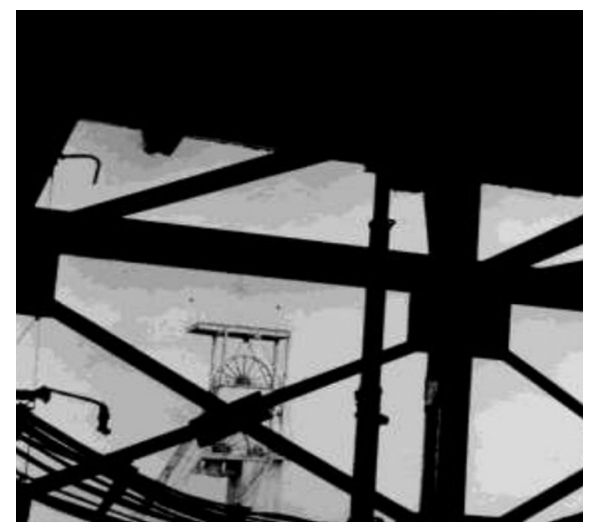

$b$

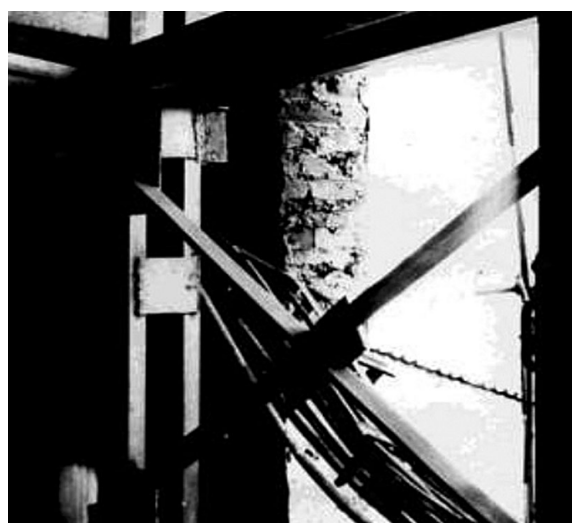

Fig. 4. The main supporting beam, raising by shaft lining upwards $(a)$ and the rack of the supporting panel and unmounted wall $(b)$.
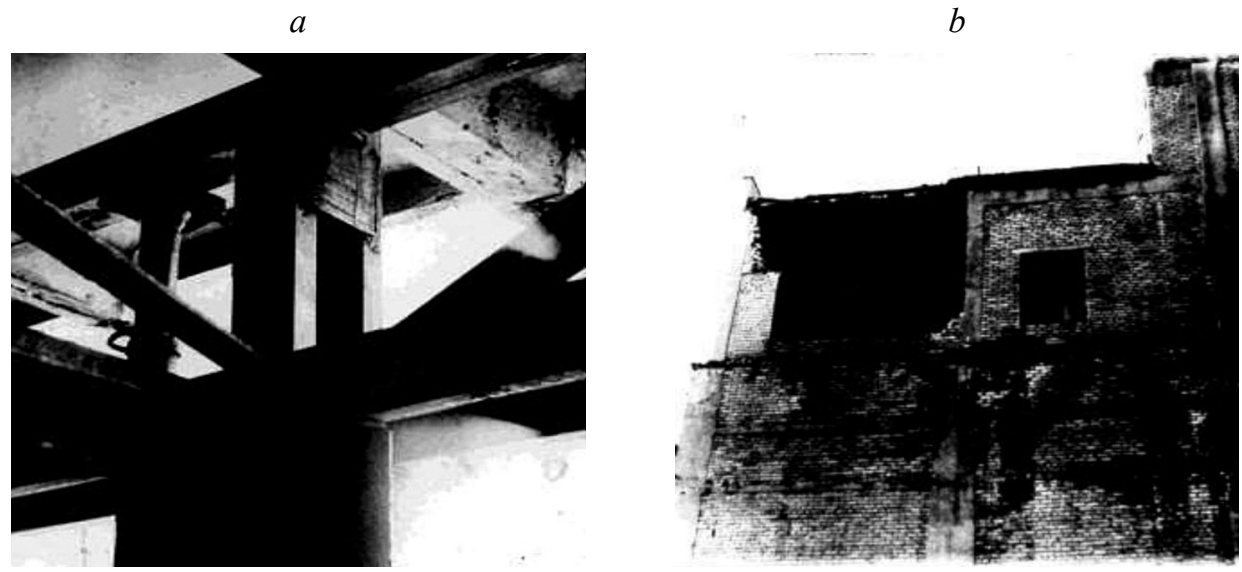

Fig. 5. The lifting supporting beam and hydraulic shaft lining $(a)$ and completely unmounted loadbearing wall of the building of the bunker $(b)$. 


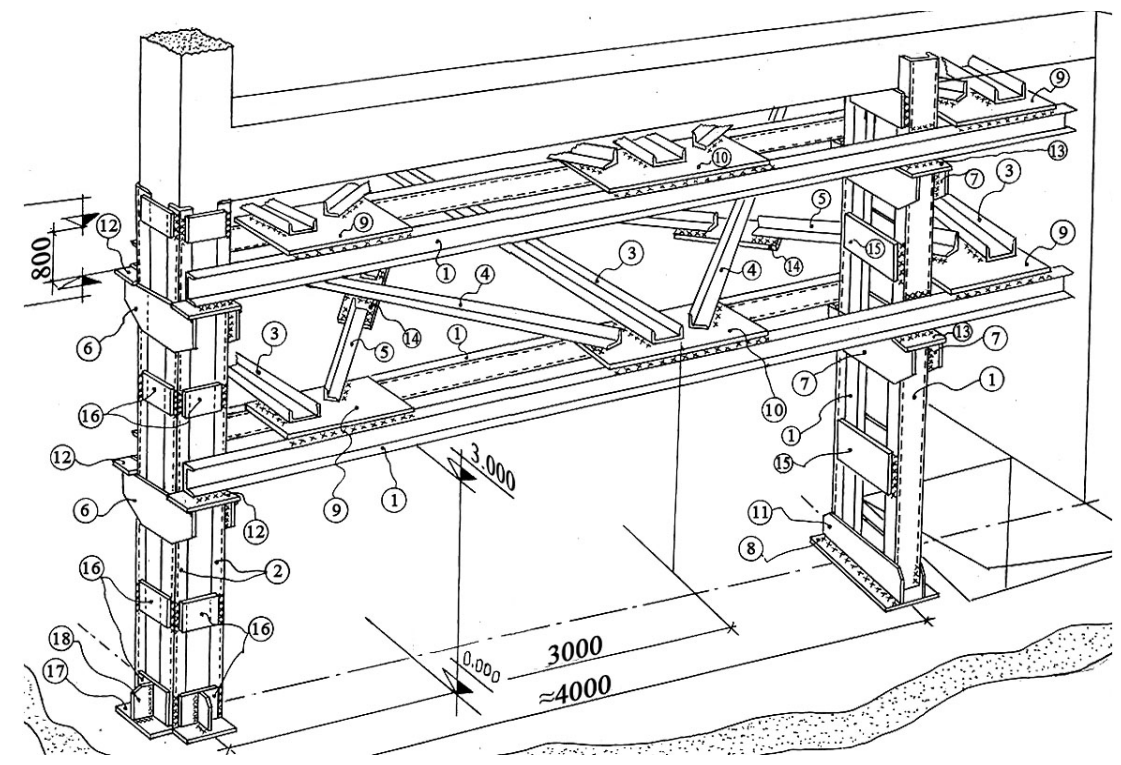

Fig. 6. The panel of the provision of stability of the system, where $1,2, \ldots, 18$ are numbers of steel members.

Table 1 contains the specification of the steel members that need for the system. More details can be found in [27].

Table 1. The members' specification.

\begin{tabular}{|c|c|c|c|c|c|}
\hline Position & Cross-section, mm & Length, mm & Quantity & Weight of item, kg & Weight, kg \\
\hline 1 & Channel 16 & 6000 & 6 & 85.2 & 511 \\
\hline 2 & Corner $75 \times 75 \times 5$ & 6000 & 4 & 34.8 & 139 \\
\hline 3 & Channel 16 & 5000 & 6 & 71.0 & 426 \\
\hline 4 & Corner $75 \times 75 \times 5$ & 5800 & 2 & 33.6 & 67 \\
\hline 5 & Corner $75 \times 75 \times 5$ & 2900 & 4 & 16.8 & 67 \\
\hline 6 & Sheet $250 \times 10$ & 750 & 4 & 14.7 & 59 \\
\hline 7 & Sheet $250 \times 10$ & 750 & 4 & 14.7 & 59 \\
\hline 8 & Sheet $300 \times 10$ & 700 & 1 & 16.5 & 17 \\
\hline 9 & Sheet $630 \times 8$ & 500 & 4 & 19.8 & 79 \\
\hline 10 & Sheet $630 \times 8$ & 700 & 2 & 27.7 & 55 \\
\hline 11 & Sheet $170 \times 8$ & 700 & 2 & 7.5 & 15 \\
\hline 12 & Sheet $160 \times 8$ & 500 & 4 & 5.0 & 20 \\
\hline 13 & Sheet $160 \times 8$ & 230 & 4 & 2.3 & 9 \\
\hline 14 & Sheet $150 \times 8$ & 460 & 4 & 4.3 & 17 \\
\hline 15 & Sheet $250 \times 6$ & 500 & 6 & 5.8 & 35 \\
\hline 16 & Sheet $200 \times 6$ & 360 & 16 & 3.4 & 54 \\
\hline 17 & Sheet $110 \times 6$ & 440 & 4 & 2.3 & 9 \\
\hline 18 & Sheet $110 \times 6$ & 190 & 4 & 0.9 & 4 \\
\hline
\end{tabular}

On the grounds of wordings and analysis of the initial conditions of the realization of the reconstruction was chose the unique strategy of the full changing wall without stopping 
of the main technological process o the building of the bunker.

This approved method can be recommended for changing of the load-carrying walls of the upper floors of any high-rise industrial buildings, which quite often decay under influence natural climatic factors.

\section{Conclusions}

In the article is the method of changing the load-bearing brick wall of the bunker's building of the mine "Oktiabrska". Also, the algorithm of the choice of the method of the reconstruction is stated, as well as complemented analysis of the "initial conditions" of the reconstruction on the base of the analysis existing methods of reconstruction and reinforcements brick structures.

For the wording of the collections of the initial conditions necessary detailed to study presence beside customer of the equipment, which can be used for the realization of the elected method of the reconstruction. Also necessary to study the nomenclature of metal, which there is on storehouse beside customer. Two of these factors allow vastly reduce expenses of the customer on the realization of the reconstruction.

On shaping the "initial conditions" of the reconstruction renders influence a possibility stops of the production process in the zone of the reconstructions, or absence of such possibility. Also necessary to analyze the possibility of access to the object of the reconstructions with medicine to be taken externally and the inner face of the building. In the event of possibility of the access with medicine to be taken externally sides of the building, the number of variants of the reinforcement increases.

However, in this case, necessary fence o the dangerous zone at a rate of land and prohibition of the execution of all work on below-located tiers.

Accounting of all "initial conditions" has logically brought about a conclusion about the need for the changing of load-bearing wall within the upper floor of the bunker's building. It was reached using the metallic spatial system, equipped by hydraulic shaft lining. This supporting system was made directly at the place of installation. Whereas the main technological process of the bunker's building is accompanied separation big amount coal dust, which can bring about blast during the production of the fire work, special events on suppression of dust and creation perfected ventilation was organized.

As a result of careful complex account all acting factors and restrictions, the main purpose of the reconstruction (changing of the load-beer wall of the upper floor of the bunker's building without stopping the main technological process) was successfully reached.

Practical approbation of the given method of reconstruction has shown that it can be recommended to broad use for changing of load-bearing walls of the upper floors of industrial buildings.

This work was conducted within the joint project "The creation of novel effective resource-saving designs for the renovation of structures in different sectors of the economy, as well as develop the energy-saved technology of construction".

\section{References}

1. Akhoundi, F., Vasconcelos, G., \& Lourenço, P. (2020). Experimental out-of-plane behavior of brick masonry infilled frames. International Journal of Architectural Heritage, 14(2), 221-237. https://doi.org/10.1080/15583058.2018.1529207

2. Alecci, V., Barducci, S., D'Ambrisi, A., De Stefano, M., Focacci, F., Luciano, R., \& Penna, R. (2019). Shear capacity of masonry panels repaired with composite materials: Experimental and 
analytical investigations. Composites Part B: Engineering, (171), 61-69. https://doi.org/10.1016/j.compositesb.2019.04.013

3. Sena da Fonseca, B., Ferreira Pinto, A.P., \& Vaz Silva, D. (2020). Compositional and textural characterization of historical bedding mortars from rubble stone masonries: Contribution for the design of compatible repair mortars. Construction and Building Materials, (247), 118627. https://doi.org/10.1016/i.conbuildmat.2020.118627

4. Garcia-Ramonda, L., Pelá, L., Roca, P., \& Camata, G. (2020). In-plane shear behaviour by diagonal compression testing of brick masonry walls strengthened with basalt and steel textile reinforced mortars. Construction and Building Materials, (240), 117905. https://doi.org/10.1016/j.conbuildmat.2019.117905

5. Grande, E., Milani, G., Bertolesi, E., Fagone, M., \& Rotunno, T. (2020). Modeling of the Tensile Behavior FRCM Systems for Repair and Strengthening Interventions of Masonry Structures. Frontiers in Built Environment, (6), 51. https://doi.org/10.3389/fbuil.2020.00051

6. Hulimka, J., Kałuża, M., \& Kubica, J. (2018). Failure and overhaul of a historic brick tower. Engineering Failure Analysis, 102, 46-59. https://doi.org/10.1016/j.engfailanal.2019.04.011

7. Lv, H., Xie, H., Zhou, S., \& Lei, S. (2014). Study on Deterioration Mechanism and Prevention and Curing Techniques of an RC Bunker. In 4th International Conference on the Durability of Concrete Structures (pp. 369-375). West Lafayette, Indiana, USA: Purdue University.

8. Marian, D.P., Onica, I., Marian, R.R., \& Floarea, D.A. (2020). Finite Element Analysis of the State of Stresses on the Structures of Buildings Influenced by Underground Mining of Hard Coal Seams in the Jiu Valley Basin (Romania). Sustainability, 12(4), 1598. https://doi.org/10.3390/su12041598

9. Nowak, R., \& Orłowicz, R. (2020). Testing of Chosen Masonry Arched Lintels. International Journal of Architectural Heritage, 1-15. https://doi.org/10.1080/15583058.2020.1735573

10. Rodriguez Mayorga, E., Cobo, A., Yanes, E., \& Saez, A. (2019). The Repair of the Structure of Santiago's Church (Jerez De La Frontera, Spain) Using Grout-Injection. International Journal of Architectural Heritage, 13(8), 1234-1251. https://doi.org/10.1080/15583058.2018.1515273

11. Verderame, G. M., Balsamo, A., Ricci, P., Di Domenico, M., \& Maddaloni, G. (2019). Experimental assessment of the out-of-plane response of strengthened one-way spanning masonry infill walls. Composite Structures, (230), 111503. https://doi.org/10.1016/j.compstruct.2019.111503

12. Khan, W., Akhtar, S., \& Hussain, A. (2019, September). Rehabilitation of concrete and masonry structures. In AIP Conference Proceedings, 2158(1), 020028. https://doi.org/10.1063/1.5127152

13. Ming, Z.Z., Bao, Z.R., \& Jiang, W.L. (2019, October). Study and application of joint layout of underground coal bunker and gangue bin in Guotun coal mine. In IOP Conference Series: Earth and Environmental Science, 330(3), 032060. https://doi.org/10.1088/1755-1315/330/3/032060

14. Canadian Standards Association (CSA). (1994). Masonry design for buildings. CSA Standard S304. 1-94, Rexdale, Ontario, Canada.

15. Canadian Standards Association (CSA). (1994). Mortar and Grout for Unit Masonry. A179-94, Rexdale, Ontario, Canada.

16. Jafari, S., Esposito, R., \& Rots, J.G. (2018). A comparative study on different testing methods to evaluate the compression properties of masonry. In Proceedings of the $10^{\text {th }}$ International Masonry Society Conferences (pp. 1421-1431). Milan, Italy.

17. Monni, F. (2018). Innovative masonry strengthening techniques maintaining the original brickwork appearance: An overview. Rehabend, 221479, 2215-2222.

18. Penazzi, D., Valluzzi, M.R., Saisi, A., Binda, L., \& Modena, C. (2001). Repair and strengthening of historic masonry buildings in seismic areas. In Proc. Int. Millennium Congress "More than two thousand years in the history of architecture safeguarding the structure of our architectural heritage" (pp. 1-7). Bethlehem, Palestine.

19. Wang, X., Xie, W., Bai, J., Jing, S., \& Su, Z. (2019). Large-Deformation Failure Mechanism of Coal-Feeder Chamber and Construction of Wall-Mounted Coal Bunker in Underground Coal Mine with Soft, Swelling Floor Rocks. Advances in Civil Engineering, 2019, 1-16. https://doi.org/10.1155/2019/6519189 
20. Yuan, Y.S., Qin, J., \& Yang, S.C. (1999). Structural protection system of masonry house for resisting ground movement induced by coal mining. Journal of China University of Mining\&Technology, 28(6), 530-534.

21. Costa, A.A., Arêde, A., Costa, A., \& Oliveira, C.S. (2011). In situ cyclic tests on existing stone masonry walls and strengthening solutions. Earthquake Engineering \& Structural Dynamics, 40(4), 449-471.

22. Karabulut, S. Non-destructive methods for determining weathering in historical monuments: a case study from Merv City, Turkmenistan. Yerbilimleri Dergisi, 40(2), 210-233. https://doi.org/10.17824/yerbilimleri.533430

23. Netinger Grubeša, I., Teni, M., Krstić, H., \& Vračević, M. (2019). Influence of freeze/thaw cycles on mechanical and thermal properties of masonry wall and masonry wall materials. Energies, 12(8), 1464. https://doi.org/10.3390/en12081464

24. Tang, Y., Shao, Z., \& Xu, T. (2018). Uniaxial compressive tests on ancient brick masonry from heritage buildings under unsaturated freeze-thaw conditions. Construction and Building Materials, (183), 706-715. https://doi.org/10.1016/j.conbuildmat.2018.06.157

25. Uranjek, M., \& Bokan-Bosiljkov, V. (2015). Influence of freeze-thaw cycles on mechanical properties of historical brick masonry. Construction and building Materials, (84), 416-428. https://doi.org/10.1016/j.conbuildmat.2015.03.077

26. Zheng, S., Song, Z., \& Zhao, P. (2016). Influence of Freeze-Thaw Cycle on Compressive Behaviors of Recycled Concrete Brick Masonry. Journal of Building Materials, 19(1), 131-136. https://doi.org/10.3969/j.issn.1007-9629.2016.01.022

27. Shushkevich, V.I. (1992). Inspection of the technical condition of the load-bearing walls of the upper floor of the bunker building with the development of reinforcement drawings, repair technology, and recommendations for further safe operation. Steel structures. Research Report. 